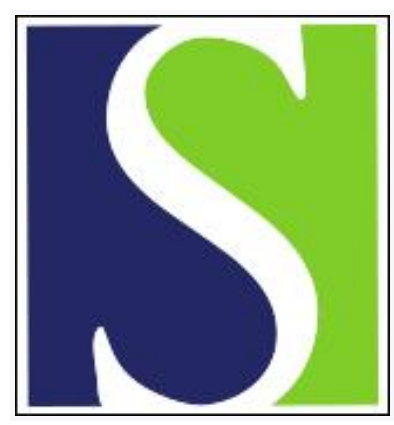

Scand J Work Environ Health 2000;26(1):26-31

https://doi.org/10.5271/sjweh.506

Issue date: Feb 2000

A forward-facilitating influence of cortisol on catecholamines assessed during the work of garbage collectors

by Sluiter JK, Frings-Dresen MHW, van der Beek AJ

Key terms: adrenaline; catecholamine; cortisol; garbage collector; noradrenaline; psychosocial factor; stress; work; work characteristic; workload

This article in PubMed: www.ncbi.nlm.nih.gov/pubmed/10744174

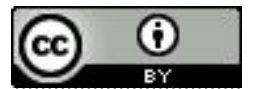




\title{
A forward-facilitating influence of cortisol on catecholamines assessed during the work of garbage collectors
}

\author{
by Judith K Sluiter, PhD, ${ }^{1}$ Monique HW Frings-Dresen, PhD, ${ }^{1}$ Allard J van der Beek, PhD'
}

\begin{abstract}
Sluiter JK, Frings-Dresen MHW, van der Beek AJ. A forward-facilitating influence of cortisol on catecholamines assessed during the work of garbage collectors. Scand J Work Environ Health 2000;26(1):26-31.

Objectives In this study, the hypothesis was tested of whether part of the hypothalamic-pituitary-adrenal system can have a facilitating influence on mean adrenomedullary reactivity during a workday.

Methods Data of a field study on 115 male garbage collectors were used for this purpose. Catecholamines and cortisol were assessed by urinary sampling during a workday and during a day off. The within-subjects baseline levels of the catecholamines, personal factors, physical work load, and work characteristics were controlled for in the analyses.

Results The results showed that there is reason to assume a "forward-facilitating influence" between the aforementioned systems. The morning cortisol excretion rate explained a reasonable amount of the mean catecholamine excretion rates during a workday. The morning cortisol level explained more variance in the adrenaline than in the noradrenaline values, and for both catecholamines the influence of cortisol was more pronounced than the influence of psychosocial stress factors like autonomy and job demands.

Conclusions The morning level of cortisol proved to be a more powerful predictor of the reactivity of adrenaline than that of noradrenaline during work. The association between the pituitary adrenocortical system and the adrenomedullary system could therefore be a "forward-facilitating influence". It is recommended that future research should focus on cortisol as the predictor of neuroendocrine reactivity and on determining whether this predictive power is expandable to work-induced health complaints.
\end{abstract}

Key terms adrenaline, cortisol, noradrenaline, psychosocial factors, stress, work characteristics, work load.

One out of four workers feels stressed by work, and one out of every five workers experiences work-related fatigue (1). In The Netherlands, work-related chronic fatigue with additional health complaints is the reason for an average yearly sickness absence of 3 months for a reasonable proportion of the working population (2). Lack of autonomy (control) appears to be a work-related psychosocial stress factor. Perceived stress increases when high job demands occur in interaction with low control on the job (3). Bodily reactions from work stress include increased activity levels in most subsystems.

Psychophysiological measurements play an important role in the examination of the interaction between work, stress, and health (4-6). In studies on work stress, the neuroendocrine parameters mostly used in monitoring human reactions to different activities are adrenaline, noradrenaline, and cortisol. It is well known that anticipatory orientation towards a stressor of personal relevance is among the most important stimulants of the hypothalamus-pituitary-adrenal (HPA) axis (7). A low degree of perceived control, for example, will prolong the normal habituation of the stress response (8). Interindividual differences in HPA activity have been observed for cortisol levels, both at rest (base line) and during work. Especially the morning base-line values have been found to vary with chronic or traumatic stress and to be associated with genetic and personality traits (7). Additional neuroendocrine responses to stressors are reactions of the sympathetic adrenomedullary system. The catecholamine levels during work are indicators of general arousal as a functional adaptation in mental (adrenaline) and physical (noradrenaline) work situations to which the subject is exposed. The ratio between adrenaline and noradrenaline excretion can be used as a representation of the nature of the work load (9). During the first hours after work, the spillover of catecholamine reactivity is often present, which indicates incomplete recovery from occupationally exerted efforts. Increases in

1 Coronel Institute for Occupational and Environmental Health, Academic Medical Center, University of Amsterdam, Amsterdam, The Netherlands.

Reprint requests to: Dr Judith Sluiter, Coronel Institute for Occupational and Environmental Health, Academic Medical Center, University of Amsterdam, PO Box 22700, 1100 DE Amsterdam, The Netherlands. [E-mail: j.sluiter@amc.uva.nl] 
adrenomedullary activity, assessed by plasma adrenaline levels, often correlate more closely with increases in pituitary-adrenocortical activity, represented by plasma levels of corticotropin (ACTH), than with increases in sympathoneural activity, as indicated by plasma noradrenaline levels (10).

Associations between cortisol excretion and the sympathetic adrenomedullary system in humans are often proposed, but the relationship is not always clear $(10,11)$. A line of reasoning could be followed according to which these associations are thought to be the modifying factor of the vicious circle in the development of chronic fatigue complaints. The morning base-line cortisol concentrations vary with the chronic or traumatic stress level, and these circadian peak values occur before the natural increase in catecholamine. Therefore, it could be possible that the cortisol peak value influences the mean excretion rates of catecholamines and that the spillover effects of catecholamines could serve as an additional stressor, causing the cortisol base line to be heightened the following day. Thus a "forward-facilitating influence" is hypothesized, according to which the early morning peak level of cortisol is thought to have a facilitating influence on the mean excretion rate of adrenaline during the day. It is further hypothesized that the morning excretion level of cortisol has a greater predictive power for the mean excretion rate of adrenaline than for the mean excretion rate of noradrenaline because adrenaline reflects mental work load.

The purpose of this study, therefore, was to investigate the facilitating influence of cortisol on adrenomedullary reactivity. This influence was tested on data from a field study among garbage collectors. The base-line levels of the catecholamines, personal factors, physical work load, and work characteristics were controlled for.

\section{Subjects and methods}

\section{Design and population}

A cross-sectional design with repeated measurements was used. The subjects were examined in the laboratory [for the assessment of body weight, body height, and maximum heart rate $\left(\mathrm{HR}_{\max }\right)$ ]. The subjects were examined in their natural (work) environment for the neuroendocrine measurements during work and in the off-work situation, and the assessment of heart rate during work. The study population consisted of 115 male garbage collectors working throughout The Netherlands for 29 different companies. They were randomly selected and informed about the procedures to be followed. The inclusion criteria were (i) collection of garbage at least 4 days a week according to the same method and (ii) a minimum of 1 year of experience. The mean age of the collectors was
37 (SD 8.7, range 22-57) years. Their mean weight was 82 (SD 14.9, range 57-128) kilograms, and their mean height was 1.78 (SD 7.6, range 1.54-1.95) meters. Their mean body mass index (BMI) was 26.1 (SD 4.1, range $19.6-40.4) \mathrm{kg} / \mathrm{m}^{2}$.

\section{Work-related variables}

Each garbage collector completed a questionnaire concerning work conditions. Dutch versions of scales concerning job demands and autonomy were included (3). The sum scores of the scales were transformed into $Z$ scores.

\section{Physical work load}

The $\mathrm{HR}_{\max }$ was determined in the laboratory using a maximal treadmill test (described in reference 12). In the natural work environment, the heart rate (beats/min) was continuously recorded and averaged every 15 seconds (Sport tester PE 3000, Polar Electro, Finland) during the whole workday to get an indication of the relative work load of the activities during the day. First, for each subject, the mean heart rate was calculated for the workday. Hereafter, the percentage of the maximum heart rate $\left(\% \mathrm{HR}_{\text {max }}\right)$ was calculated by dividing the mean heart rate of the workday by the $\mathrm{HR}_{\max }$ and multiplying this outcome by 100 . The mean heart rate during the workday was 105 (SD 12.0, range 79-132) beats/min, and the mean $\% \mathrm{HR}_{\text {max }}$ during the workday was 57 (SD 6.8, range $43-75) \%$.

\section{Catecholamine and cortisol measurements}

Procedure. Excretion rates of catecholamines and cortisol were assessed during a workday and a rest day (a Sunday). The subjects were asked to collect all urine during these days and to provide samples (i) around 0700 , (ii) around the lunch break (1100), (iii) around the end of the workday (1530), (iv) around 2000, and (v) before going to bed. The times of all the urinations were recorded during the 2 days. The analyses were performed on samples ii, iii, and iv. Samples ii and iii reflected the hours of work in the morning and afternoon, respectively. Sample iv reflected the first recovery hours after work.

Analysis. The subjects were asked to urinate into a jar that contained 0.7 grams of citric acid. First, the volume of each urine sample was assessed. Second, $40 \mathrm{ml}$ from each sample was kept, of which $20 \mathrm{ml}$ was acidified with 0.1 milliliters of $10 \mathrm{M}$ hydrochloric acid for the catecholamine analyses. These $20-\mathrm{ml}$ samples were kept frozen $\left(-20^{\circ} \mathrm{C}\right)$ until analysis. The urinary catecholamine concentrations were determined by high-performance liquid chromatography with fluorescence detection (13). The 
urinary cortisol concentrations were determined by the Amersham amerlite cortisol assay, which uses a competitive immunoassay technique, based on enhanced luminescence (14).

\section{Data analysis and statistics}

First, the urinary concentrations (nanograms per milliliter) were multiplied by the volume of the corresponding urine sample. This amount was divided by the period of time (minutes) between the urination of the sample and the previous urination time, to obtain the mean excretion rate (nanograms per minute) for an exact period of time. Second, a repeated-measures analysis of variance (MANOVA, F test, correcting with Mauchly's test for sphericity) was performed for each day to test whether there were diurnal differences. To evaluate the reactivity of the catecholamines and cortisol, the mean urinary excretion rates for the workday and the rest day (base line) were calculated for adrenaline and noradrenaline. In all the analyses the differences were accepted as significant at $\mathrm{P}<0.05$. To test our hypothesis, hierarchical multiple linear regression analyses were carried out for both the catecholamines, with the mean excretion rate on the workday as the dependent variable. The mean excretion rates of the catecholamines on the rest day and the morning levels of cortisol on the workday were entered

Table 1. Overall mean excretion rate of adrenaline, noradrenaline, and cortisol per day among garbage collectors ( $N=115)$.

\begin{tabular}{|c|c|c|c|c|c|c|}
\hline & \multicolumn{2}{|c|}{$\begin{array}{l}\text { Adrenaline } \\
\text { (ng/min) }\end{array}$} & \multicolumn{2}{|c|}{$\begin{array}{l}\text { Noradrenaline } \\
\quad(\mathrm{ng} / \mathrm{min})\end{array}$} & \multicolumn{2}{|c|}{$\begin{array}{c}\text { Cortisol } \\
\text { (ng/min) }\end{array}$} \\
\hline & Mean & SD & Mean & SD & Mean & $\mathrm{SD}$ \\
\hline Workday & 12.40 & 5.49 & 65.76 & 20.75 & 107.64 & 44.22 \\
\hline Rest day & 7.86 & 4.02 & 42.92 & 13.50 & 107.72 & 42.07 \\
\hline
\end{tabular}

into the model in the first step as independent variables. The variables age, $\mathrm{BMI}$ and $\% \mathrm{HR}_{\mathrm{max}}$ were entered into the model in the second step. In the third step, the variables concerning job demands and autonomy were entered into the model. To be able to control for collinearity, tolerance levels were checked in the models of the third step.

\section{Results}

\section{Catecholamines and cortisol}

For adrenaline and cortisol, circadian rhythmicity was notable on both days $(\mathrm{P}<0.05$ for both days). For noradrenaline, the workday showed circadian rhythmicity $(\mathrm{P}<0.01)$, but no circadian rhythm was found on the rest day. Table 1 shows the mean excretion rates for adrenaline, noradrenaline, and cortisol for each day. The overall mean excretion rates of adrenaline and noradrenaline on the workday were significantly higher than on the rest day $(\mathrm{P}<0.01)$. For cortisol, no differences were found between the workday and the rest day.

In tables 2 and 3 the results are presented of the hierarchical multiple regression analyses. Table 2 shows that, in the first step, $46 \%$ of the variance in the mean adrenaline excretion rate on the workday was explained by the morning level of cortisol and the base-line value of adrenaline. In the following stage, a marginal significant increase in the coefficient of determination $(\mathrm{P}=0.06) \mathrm{oc}-$ curred when the variables age, $\mathrm{BMI}$, and $\% \mathrm{HR}_{\max }$ were entered into the regression model. The variable $\% \mathrm{HR}_{\max }$ contributed significantly. The 3rd step showed a significant increase in the coefficient of determination $(\mathrm{P}=0.03)$ when the variables job demands and autonomy were entered. Only autonomy contributed significantly in

Table 2. Stepwise multiple regression with the adrenaline excretion rate of the garbage collectors on the workday as the dependent variable and the adrenaline excretion rate on the rest day, the morning level of cortisol, age, percentage of the maximum heart rate $\left(\% \mathrm{HR}_{\max }\right)$, body mass index (BMI), work demands, and autonomy as independent variables $(\mathrm{N}=115)$.

\begin{tabular}{|c|c|c|c|c|c|c|}
\hline & \multicolumn{2}{|c|}{ Step one } & \multicolumn{2}{|c|}{ Step two } & \multicolumn{2}{|c|}{ Step three } \\
\hline & $\begin{array}{l}\text { Standardized } \\
\text { regression } \\
\text { coefficient (beta) }\end{array}$ & $\begin{array}{c}\text { P-value of } \\
\text { t-test }\end{array}$ & $\begin{array}{l}\text { Standardized } \\
\text { regression } \\
\text { coefficient (beta) }\end{array}$ & $\begin{array}{c}\text { P-value of } \\
\text { t-test }\end{array}$ & $\begin{array}{l}\text { Standardized } \\
\text { regression } \\
\text { coefficient (beta) }\end{array}$ & $\begin{array}{c}\text { P-value of } \\
\text { t-test }\end{array}$ \\
\hline Rest day adrenaline & 0.38 & 0.00 & 0.36 & 0.00 & 0.34 & 0.00 \\
\hline Morning level cortisol & 0.51 & 0.00 & 0.47 & 0.00 & 0.50 & 0.00 \\
\hline Age & & & -0.11 & 0.15 & -0.11 & 0.12 \\
\hline$\% \mathrm{HR}_{\max }$ & & & 0.16 & 0.03 & 0.15 & 0.04 \\
\hline BMI & & & 0.13 & 0.08 & 0.11 & 0.11 \\
\hline Work demands & & & & & 0.03 & 0.64 \\
\hline Autonomy & & & & & 0.18 & 0.01 \\
\hline Coefficient of determination & 0.46 & & 0.50 & & 0.53 & \\
\hline Signiticance of change & & 0.06 & & 0.03 & & \\
\hline$F$ of regression equation & 48.55 & & 21.80 & & 17.36 & \\
\hline Significance of $F^{a}$ & 0.00 & & 0.00 & & 0.00 & \\
\hline
\end{tabular}

a P-values, Durbin-Watson test $=1.97$. 
explaining the variance in the mean adrenaline excretion rate on the workday. The tolerance figures were above 0.82 for all the independent variables.

Table 3 shows the outcomes of the hierarchical multiple regression analysis, in which the excretion rate of noradrenaline was used as a dependent variable. The morning cortisol value and the base-line value of noradrenaline accounted together for $19 \%$ of the explained variance in the mean noradrenaline excretion rate on the workday. A significant increase in the coefficient of determination occurred by the 2 nd step when the variables age, $\mathrm{BMI}$, and $\% \mathrm{HR}_{\max }$ were entered into the regression model (from 0.19 to $0.31, \mathrm{P}=0.00$ ). In the 3 rd step no significant contributions to the explained variance occurred with the entering of the variables job demands and autonomy. The tolerance figures were above 0.81 for all the independent variables.

\section{Discussion}

Neuroendocrine reactivity during a workday and a rest day, work characteristics, and physical work load were assessed in a field study of 115 Dutch garbage collectors.

As in other field studies $(4,15-21)$, the measurement of catecholamines took place via urine for an overall view of the reactivity over large time periods. Cortisol has been measured more often in saliva (22-28). Investigating cortisol by urine sampling is preferred when an overall picture of cortisol reactivity is the purpose of the study. In urine, the excretion rate is measured over an exact period of time between 2 urinations.

The absolute mean values of adrenaline and noradrenaline during the workday and during the rest day were the same as found in a comparable field study on 32 truck drivers (20). Most field studies in which comparable neuroendocrine assessments have been undertaken have contained far fewer subjects because of the time-consuming character and costs of this kind of research. The rest day was assessed as base line. To get a more precise picture of recovery from work, it is recognized that it would have been more desirable to assess a consecutive day off between the workday and the resting day as well.

The work of garbage collectors is characterized by physical exertion and low control over the sequence of task performance. The laboratory measurements of the $\mathrm{HR}_{\max }$ by means of a maximal treadmill test made it possible to get an appropriate indication of the individual relative physical work load of the activities during the day by calculating the percentage of the maximum heart rate $\left(\% \mathrm{HR}_{\max }\right)$. The physical nature of the job was confirmed by the significantly explained variance in noradrenaline reactivity by the $\% \mathrm{HR}_{\max }$ and BMI. This last finding was also found by Van der Beek et al (20). The excretion rate of noradrenaline is known to be a better indicator of physical than of psychological load. In addition, it is said that plasma and urinary noradrenaline should not be used as indicators of the sympathetic effects of psychological activation (29). Both the significant influence of $\% \mathrm{HR}_{\max }$ and $\mathrm{BMI}$ on the mean noradrenaline excretion rate, and the finding that work characteristics had more impact on adrenaline than noradrenaline, confirmed the existing knowledge (29).

Possibly due to the similarity in the work demands of the garbage collectors, and the therefore minor variation in the scale scores, no influence of job demands on the catecholamine excretion rates was found. More contrast was found in the scale scores on autonomy. The level of autonomy alone is also known to influence experienced work stress (3). This influence was confirmed in

Table 3. Stepwise multiple regression with the noradrenaline excretion rate on the workday of the garbage collectors as the dependent variable and the noradrenaline excretion rate on the rest day, the morning level of cortisol, age, percentage of maximum heart rate $\left(\% H R_{\max }\right)$, body mass index $(B M I)$, work demands, and autonomy as independent variables $(N=115)$.

\begin{tabular}{|c|c|c|c|c|c|c|}
\hline & \multicolumn{2}{|c|}{ Step one } & \multicolumn{2}{|c|}{ Step two } & \multicolumn{2}{|c|}{ Step three } \\
\hline & $\begin{array}{l}\text { Standardized } \\
\text { regression } \\
\text { coefficient (beta) }\end{array}$ & $\begin{array}{c}\text { P-value of } \\
\text { t-test }\end{array}$ & $\begin{array}{l}\text { Standardized } \\
\text { regression } \\
\text { coefficient (beta) }\end{array}$ & $\begin{array}{c}\text { P-value of } \\
\text { t-test }\end{array}$ & $\begin{array}{l}\text { Standardized } \\
\text { regression } \\
\text { coefficient (beta) }\end{array}$ & $\begin{array}{c}\text { P-value of } \\
\text { t-test }\end{array}$ \\
\hline Rest day noradrenaline & 0.33 & 0.00 & 0.23 & 0.01 & 0.23 & 0.01 \\
\hline Morning level cortisol & 0.21 & 0.02 & 0.17 & 0.05 & 0.17 & 0.05 \\
\hline Age & & & -0.02 & 0.79 & -0.02 & 0.85 \\
\hline$\% \mathrm{HR}_{\max }$ & & & 0.31 & 0.00 & 0.32 & 0.00 \\
\hline BMI & & & 0.19 & 0.03 & 0.19 & 0.04 \\
\hline Work demands & & & & & 0.04 & 0.63 \\
\hline Autonomy & & & & & -0.01 & 0.91 \\
\hline Coefficient of determination & 0.19 & & 0.31 & & 0.31 & \\
\hline Significance of change ${ }^{a}$ & & 0.00 & & 0.87 & & \\
\hline$F$ of regression equation & 13.32 & & 9.85 & & 6.97 & \\
\hline Significance of $\mathrm{F}$ a & 0.00 & & 0.00 & & 0.00 & \\
\hline
\end{tabular}

a P-values, Durbin-Watson test $=2.045$. 
the study as this psychosocial work factor was found to be related to the adrenaline excretion rate during work. As adrenaline reactivity has often proved to represent mental work load, this outcome seems appropriate. Theoretically, the outcomes of the analyses could have been influenced by the fact that job demands and job control were not entered before the 3rd step. However, the tolerance figures did not indicate multicollinearity.

In this study, the hypothesis was tested of whether the morning level of cortisol could have a facilitating influence on mean adrenomedullary reactivity during a workday. Although the exact underlying mechanism remains unclear, the predictive power of the morning level of cortisol on the variance in adrenomedullary reactivity during a workday was confirmed. Together with the base-line values of the catecholamines, the morning level of cortisol on the workday explained $46 \%$ and $19 \%$ of the variance in the reactivity of adrenaline and noradrenaline, respectively. Because corticotropin excretion proved to be strongly related to cortisol excretion, this study confirmed the closer association between pituitaryadrenocortical activity with adrenomedullary activity when compared with sympathoneural activity, as was described by Goldstein (10). The "forward facilitating hypothesis" that was found in this study could have interesting implications when fundamental animal and human brain research is compared with field studies of this kind. In a review, Buijs (30) described the possibility that, next to melatonin, the corticosterone peak serves to synchronize the activity of the suprachiasmatic nucleus $(\mathrm{SCN})$ when constant dark conditions are present. Normally, the SCN controls the daily peak in plasma corticosterone and corticotropin. Earlier, Buijs et al (31) hypothesized that a circadian profile in transmitter secretion from SCN terminals is responsible for the 24-hour rhythms in hormonal and behavioral patterns. Furthermore, cell atrophy was recently found in the SCN of essential hypertension patients who had died (Buijs, preliminary results). Hypothetically, this atrophy could cause a disturbance in SCN function and therefore in the daily peak of corticosterone. Hypertension has proved to be one of the possible long-term results of chronic work stress (3). The findings of our study, therefore, could confirm that people with high peak levels of cortisol, and therefore higher mean adrenomedullary reactivity during the workday, are more at risk of developing hypertension over time.

\section{Concluding remarks}

The morning level of cortisol proved to be a more powerful predictor of reactivity in adrenaline than in noradrenaline during work. The association between the pituitary adrenocortical system and the adrenomedullary system could therefore be a "forward-facilitating influence". The level of autonomy contributed significantly to explaining adrenaline reactivity, but not noradrenaline reactivity. It is recommended that future research focus on cortisol as the predictor of neuroendocrine reactivity and to determine whether this predictive power is expandable to include work-induced health complaints.

\section{Acknowledgments}

We would like to thank Sijmen Kuiper (Coronel Institute) for the analyses of the catecholamines and cortisol.

\section{References}

1. European Foundation for the improvement of living and working conditions. Euro review. Dublin: European Foundation for the Improvement of Living and Working Conditions, 1997:6-8.

2. Engers RW, Muller B.Het ging gewoon niet meer [It just did not work anymore]. Amsterdam: General Administration Office [GAK/FVB], 1994. Report no 94.01.

3. Karasek RA, Theorell T. Healthy work: stress, productivity, and the reconstruction of working life. New York (NY): Basic Books, 1990:31-82.

4. Frankenhaeuser $M$, Lundberg U, Fredrikson $M$, Melin B, Tuomisto M, Myrsten AL, et al. Stress on and off the job as related to sex and occupational status in white-collar workers. J Organ Behav 1989:10-346.

5. Lundberg U. Methods and applications of stress research. Technol Health Care 1995;3:3-9

6. Gaillard AWK, Wientjes CJE. Evaluation of the work environment: approaches and methods. In: Ulisperger P, Ertel M, Freude G, editors. Occupational health and safety aspects of stress at modern workplaces. Berlin: Schriftenreihe der Bundesanstalt für Arbeitsmedizin, 1996;11:8—27.

7. Hellhammer DH, Kirschbaum C, Heim C, Ehlert U. Individual differences of pituitary-adrenal reactivity in men. In: Ullsperger P, Ertel M, Freude G, editors. Occupational health and safety aspects of stress at modern workplaces. Berlin: Schriftenreihe der Bundesanstalt für Arbeitsmedizin, 1996; $11: 62-5$.

8. Kirschbaum C, Platte P, Pirke K-M, Hellhammer D. Adrenocortical activation following stressful exercise: Further evidence for attenuated free cortisol responses in women using oral contraceptives. Stress Med 1996;12:137-43.

9. Gaillard AWK. Stress: Produktiviteit en gezondheid [Stress: Productivity and health]. Amsterdam: Uitgeverij Nieuwezijds, 1996:181-220.

10. Goldstein DS. Stress, catecholamines, and cardiovascular disease. Oxford: Oxford University Press, 1995:103-61.

11. Korunka C, Huemer KH, Litschauer B, Karetta B, KafkaLutzow A. Working with new technologies: hormone excretion as an indicator for sustained arousal: a pilot study. Biol Psychol 1996;42:439-52.

12. Frings-Dresen MHW, Kemper HCG, Stassen ARA, Crolla 
IFA, Markslag AMT. The daily work load of refuse collectors working with three different collecting methods: a field study. Ergonomics 1995;38:2045-55.

13. Boos K, Wilmers B, Sauerbrey R, Schlimme E. Development and performance of an automated HPLC-analyzer for catecholamines. Chromatographia 1987;24:363-70.

14. Amersham Inc. Manual amerlite cortisol assay. Uppsala: Amersham Inc, 1973.

15. Aronsson G, Johansson G. Work content, stress and health in computer-mediated work: a seven year follow-up study. Work Disp Units 1987;86:732-8.

16. Fibiger W, Christensen F, Singer G, Kaufmann H. Mental and physical components of sawmill operatives' workload. Ergonomics 1986;29:363-75.

17. Lim CS, Ong CN, Phoon WO. Work stress of firemen as measured by heart rate and catecholamine. J Hum Ergol 1987; 16:209-18.

18. Härenstam AB, Theorell TPG. Work conditions and urinary excretion of catecholamines - a study of prison staff in Sweden. Scand J Work Environ Health 1988;14:257-64.

19. Evans GW, Carrère $S$. Traffic congestion, perceived control, and psychophysiological stress among urban bus drivers. J Appl Psychol 1991;76:658-63.

20. Van der Beek AJ, Meijman TF, Frings-Dresen MHW, Kuiper JI, Kuiper S. Lorry drivers' work stress evaluated by catecholamines excreted in urine. Occup Environ Med 1995;52:4649.

21. Sluiter JK, Van der Beek AJ, Frings-Dresen MHW. Work stress and recovery measured by urinary catecholamines and cortisol excretion in long distance coach drivers. Occup Environ Med 1998;55:407-13.

22. Houtman IL. Individual differences in reactivity to and coping with the stress of lecturing. J Psychosom Res 1991; 35:11-24.

23. Jin P. Efficacy of tai chi, brisk walking, meditation, and reading in reducing mental and emotional stress. J Psychosom Res 1992;36:361-70.

24. Motohashi Y. Alteration of circadian rhythm in shift-working ambulance personnel: monitoring of salivary cortisol rhythm. Ergonomics 1992;35:1331-40.

25. Fox ML. Effects of stressful job demands and control on physiological and attitudinal outcomes in a hospital setting. Acad Manage J 1993;36:289-318.

26. French J, Bisson RU, Neville KJ, Mitcha J, Storm WF. Crew fatigue during simulated, long duration $\mathrm{B}-1 \mathrm{~B}$ bomber missions. Aviat Space Environ Med 1994;65(5 II):A1—6.

27. Fox ML. Stressful job demands and worker health: an investigation of the effects of self-monitoring. J Appl Soc Psychol 1995;25:1973-95.

28. Burton RF, Hinton JW, Neilson E, Beastall G. Concentrations of sodium, potassium and cortisol in saliva, and self-reported chronic work stress factors. Biol Psychol 1996;42:425-38.

29. Ursin H, Knardahl S. Personality factors, neuroendocrine response patterns, and cardiovascular pathology. In: Orlebeke J, Mulder G, Van Doornen L, editors. Psychophysiology of cardiovascular control. New York (NY): Plenum Press, 1985:715-31.

30. Buijs RM. The anatomical basis for the expression of circadian rhythms: the efferent projections of the suprachiasmatic nucleus. In: Buijs RM, Kalsbeek A, Romijn HJ, Pennartz CMA, Mirmiran M, editors. Progress in brain research, 111. Amsterdam: Elsevier Science, 1996:229-39.

31. Buijs RM, Wortel J, Van Heerikhuize JJ, Kalsbeek A. Novel environment induced inhibition of corticosterone secretion: physiological evidence for a suprachiasmatic nucleus mediated neuronal hypothalamo-adrenal cortex pathway. Brain Res 1997;758:229-36.

Received for publication: 15 October 1998 